\title{
SIMULATION MODEL OF THE CONTROL SYSTEM OF PORTABLE BOXES FOR BLOOD BAGS TRANSPORT
}

\author{
Lorenzo Damiani \\ Roberto Revetria \\ Stefano Arecco \\ Department of Mechanical Engineering \\ Genoa University \\ Via Opera Pia 15, 16132 \\ Genoa, Italy \\ \{Lorenzo.Damiani,Roberto.Revetria,Ste.arecco\}@unige.it
}

\begin{abstract}
Blood transport is very important in the healthcare sector; new technologies can help implement efficient transport systems. To maintain unaltered the bio-chemical properties of blood during transports, blood bags need to be kept within a precise temperature range for the entire travel time.

This paper presents a Matlab-Simulink model of an innovative box for blood transport, including a temperature control system which employs eutectic fluid elements exchanging heat with the transported blood bags. To keep the temperature within the correct range, on-off blowers provide an air flow between the eutectic and blood compartments.

The basic idea is to equip the boxes with sensors that dialogue by cloud with a server on which the simulator is installed; this allows to continuously monitor the time remaining before the exhaustion of the eutectic cooling effect, in which case a logistic algorithm will provide the coordinates of the nearest healthcare location for blood deposition.
\end{abstract}

Keywords: simulation model, healthcare, blood transport, temperature control, Matlab-Simulink.

\section{INTRODUCTION}

According to the normal procedures, biologic samples are daily collected from distributed collection points (e.g. hospitals and healthcare centers) and delivered to a laboratory for analyses. In the last years, the increased costs and the complexity of the equipment for clinic analyses, has pushed the growth of large centralized laboratories, which serve and supply a great number of collection points distributed within large areas. Only big laboratories exploiting advanced automatized equipment can attain the required scale economies to elaborate with the proper profitability a large volume of samples per day.

Unfortunately, the average distance between collection points and laboratories is increasing, together with the risk of deterioration of the samples during transport time (Gibson et al. 1947; Or and Pierskalla 1979; Fakhr et al. 2012). A similar issue affects blood banks, which are becoming more and more centralized in order to be able to serve larger areas. From this point of view, fundamental aspects involve the protection, the traceability and the monitoring of blood bags during their transport from collection points to blood banks and from blood banks to surgeries. 
Regarding the topic of healthcare safety (Damiani et al. 2016; Damiani et al. 2017, Patrone et al. 2017), this paper focuses on the problem of blood transport, which presents risks related to the biologic material deterioration whenever well defined temperature ranges are exceeded. The solution to this problem is not only related to the design of a transport container equipped with a cooling system, but is extended to the issue of temperature control in different environmental conditions and to the not less important continuous monitoring of the material status during the travel (Castro et al. 2011), including data exchange with the central unit (hospital or blood bank) which needs to provide in real time the proper logistic indications (i.e. the nearest possible point of blood collection) to avoid deterioration.

The present article proposes an integrated system dedicated to blood transport, including a controlled temperature insulated box for blood bags transportation and a cloud monitoring system of the box status and localization. The transport box is equipped with eutectic elements confined in a compartment which, by means of a series of on-off blowers activated by the measured temperature signal, provides a stream of cold air to the compartment containing the blood bags, keeping in this way the blood within the required temperature range. The box is continuously connected by cloud with a central server unit on which is installed a dynamic simulator (described in section 3 of this paper) able to determine the thermal autonomy of the box. Contemporarily, a logistic model receiving in real time the exact geo-localization of the box, provides the coordinates of the nearest collection center in which the blood can be safely delivered in case the box ran out of autonomy.

\section{FEATURES OF THE BLOOD TRANSPORT BOX}

The controlled temperature transport box is dedicated to keeping, monitoring, tracking and certifying the quality of each component requiring a complete traceability of transport and of the care chain; in particular, the box is employed for the transport of blood and blood products (plasma, blood platelets...) bags.

The box is composed by an intelligent container constantly connected to a cloud platform for the monitoring, recording and signaling of possible failures and alert signals in real time for the main operational parameters, as:

- Internal temperature;

- External temperature;

- Tilting of the box;

- Accelerations;

- Geo-localization (GPS, GSM, GLONASS, GALILEO);

- Speed;

- Relative humidity;

- Physical integrity of the device;

- Date, time, minute and name of the responsible for each operation (switching on, loading, shipping, delivering, unloading, switching off, inspection).

The box is designed to actively maintain constant the temperature of the contained materials within a range which can be defined by the user. This functionality is ensured by the introduction in the appropriate space of particular eutectic plates, whose thermal content is released when required by a "smart wall" providing the ventilation through appropriate blowers activated by a control system installed within the box. A scheme of the box components is visible in Figure 1. 


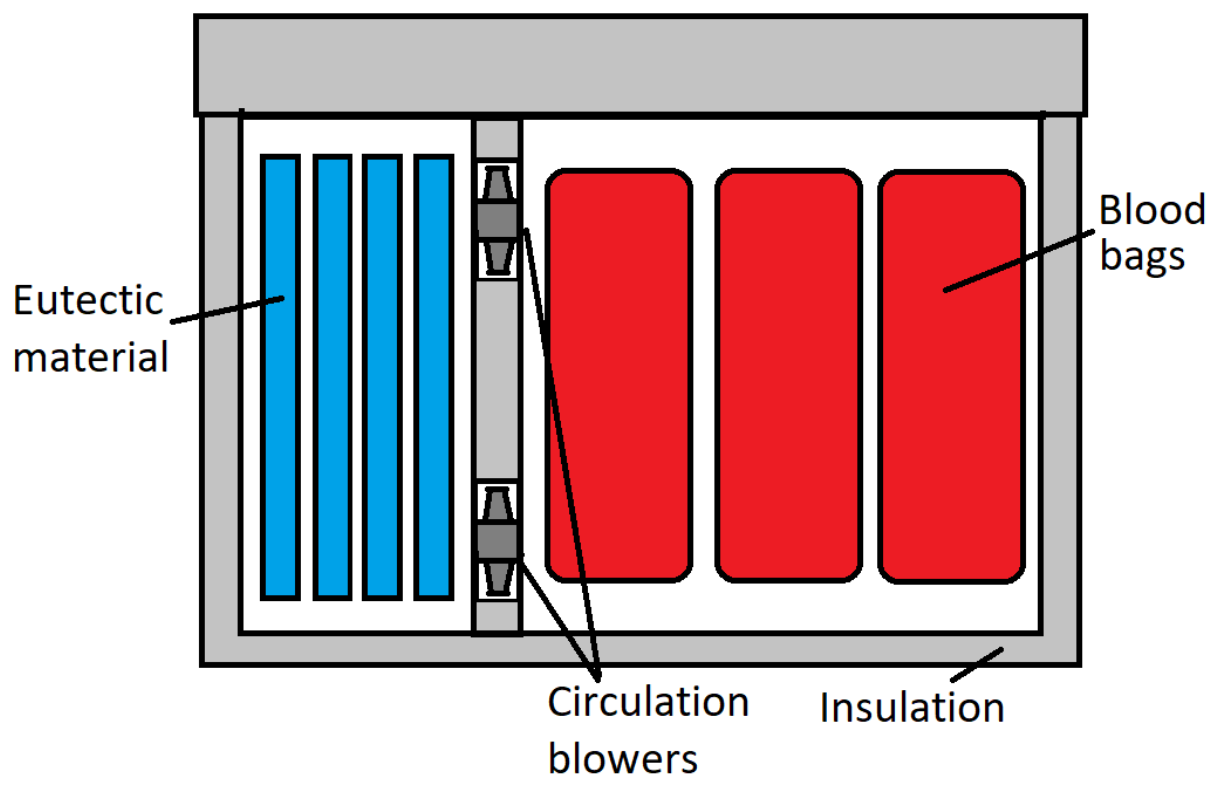

Figure 1: Scheme of the box for blood transport.

The box is not intended to perform the cooling of the introduced material; it is instead designed just for the temperature maintenance with 2 to 3 degrees in more or in less with respect to the set-point. Therefore, the transported material needs to be loaded in the box at the desired temperature. The box is designed to keep the temperature range for a time period not exceeding 5 hours.

The use of the box is possible through a LCD screen and a personal smart card, allowing to identify safely every operator and, basing on the permissions released to each person, to enable or disable the functions of opening, closing and settings modification. The box is manageable through an online portal in which, after the login, the user can monitor and interact with all the boxes assigned to his profile.

\subsection{Data exchange system}

The system performs the measurement of the various physical quantities above listed with a sampling frequency of $5 \mathrm{~Hz}$ and sends them to a central server; according to the availability of GSM network, the collected data are stored in a local memory from which they are sent to the server.

In the case of having the availability of a dedicated Wi-Fi router, the box can use this latter instead of the GSM.

In Figure 2 is visible the scheme of the network connections for data exchange. 


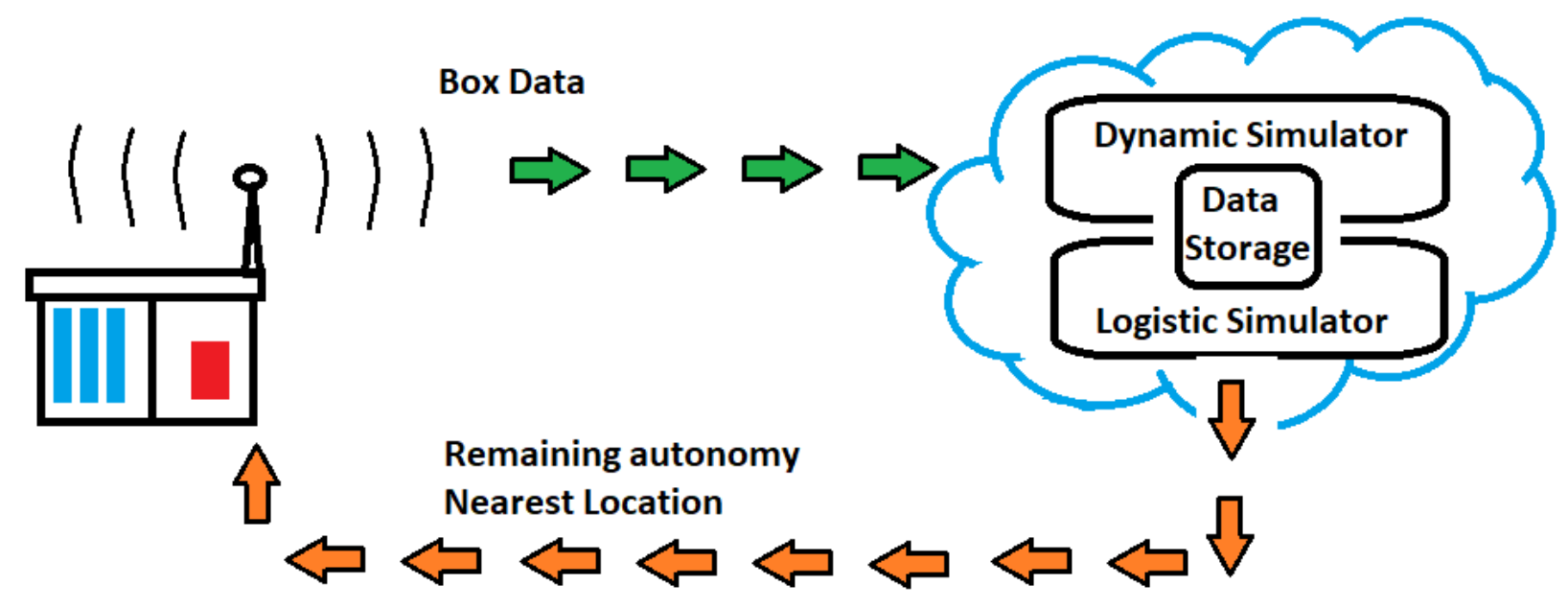

Figure 2: Scheme of the network interconnections.

\section{MATLAB-SIMULINK MODEL}

The Matlab-Simulink dynamic model (Damiani et al. 2015; Damiani and Pini Prato 2014; Dellachà et al. 2014) has the main purpose to calculate the time variation of the blood temperature together with the eutectic liquid mass fraction, that is the determining parameter of the box autonomy: once liquid mass fraction has reached the value 1 , the material can no more ensure constant temperature within the box.

Moreover, the model provides the control algorithm for switching on and off the blowers in function of the blood vane temperature (Damiani et al. 2015).

The model solves a system of differential equations: equation (1) computes the thermal balance of the blood compartment:

$$
\dot{q}_{e x t}+\dot{q}_{f}+\dot{m}_{a} c p_{a}\left(T_{e u}-T_{b l}(t)\right)=M_{b l} c p_{b l} \frac{d T_{b l}(t)}{d t}
$$

where:

$T_{b l}(t)=$ blood vane temperature, to be kept in the desired range $\left(4^{\circ} \mathrm{C}-6^{\circ} \mathrm{C}\right)$;

$T_{e u}=$ temperature of the eutectic vane, considered constant and equal to $-2.5^{\circ} \mathrm{C}$ (from measurements);

$c p_{b l}=$ blood specific heat, equal to $3900 \mathrm{~J} / \mathrm{kg} \mathrm{K}$;

$M_{b l}=$ blood mass being transported, considered equal to $7 \mathrm{~kg}$;

$\dot{m}_{a}=$ air flow rate moved by the blowers, considered equal to $0.018 \mathrm{~kg} / \mathrm{s}$;

$c p_{a}=$ air specific heat capacity, equal to $1200 \mathrm{~J} / \mathrm{kg} \mathrm{K}$;

$\dot{q}_{f}=$ blowers (fans) power; being the air loop closed, all the fans power $(4 \mathrm{~W})$ is delivered to the air;

$\dot{q}_{\text {ext }}=$ thermal flow entering the box from the external environment, calculated as in equation (2): 


$$
\dot{q}_{\text {ext }}=K_{b o x} S_{b o x}\left(T_{a m b}-\frac{T_{b l}(t)+T_{e u}}{2}\right)
$$

where:

$$
\begin{aligned}
& K_{b o x}=\text { average transmittance of the box walls; } \\
& S_{b o x}=\text { total external surface of the box; } \\
& T_{a m b}=\text { environmental temperature of transport. }
\end{aligned}
$$

Equation (1) is the differential equation describing the thermal balance of the box: the thermal flow heating up the blood (from the environment and the fans) and that transported with the circulating air, determine the temperature variation with time of the stored blood mass. Equation (2) quantifies the thermal flow coming from the external environment; in this equation, the box internal temperature is hypothesized as average between the blood and the eutectic vanes.

Equation (3) is used for computing the thermal balance of the eutectic vane:

$$
\dot{m}_{a} c p_{a}\left(T_{e u}-T_{b l}(t)\right)=M_{e u} r_{e u} \frac{d x_{e u}(t)}{d t}
$$

where:

$M_{e u}=$ mass of the eutectic material, set equal to $1 \mathrm{~kg}$;

$r_{e u}=$ latent heat of meltdown of the eutectic material, assumed as equal to $265070 \mathrm{~J} / \mathrm{kg}$;

$x_{e u}(t)=$ liquid mass fraction of the eutectic material, defined as:

$$
x_{e u}(t)=\frac{m_{l i q}}{m_{\text {liq }}+m_{\text {sol }}}
$$

$m_{\text {liq }}$ and $m_{\text {sol }}$ being respectively the liquid and the solid masses of the eutectic during transport time.

Equation (3) represents the differential equation of the eutectic meltdown, showing the variation in time of the liquid mass fraction of the eutectic material, which increases from 0 to 1.

In figure 3 is shown the scheme of the Matlab-Simulink blocks interconnected to form the complete model, namely:

- Thermal flow from environment block, implementing equation (2);

- Blowers block, commanded by the logic control system explained in the next section;

- Blood vane temperature block, implementing equation (1); the integration of temperature variation signal is carried out by an integrator with external source for the initial condition, in which must be loaded the initial temperature of the blood vane; 
- Eutectic vane temperature block, implementing equation (3), and determining, through a similar integration as the blood temperature vane block, the liquid mass fraction of the eutectic elements, defined in equation (4).

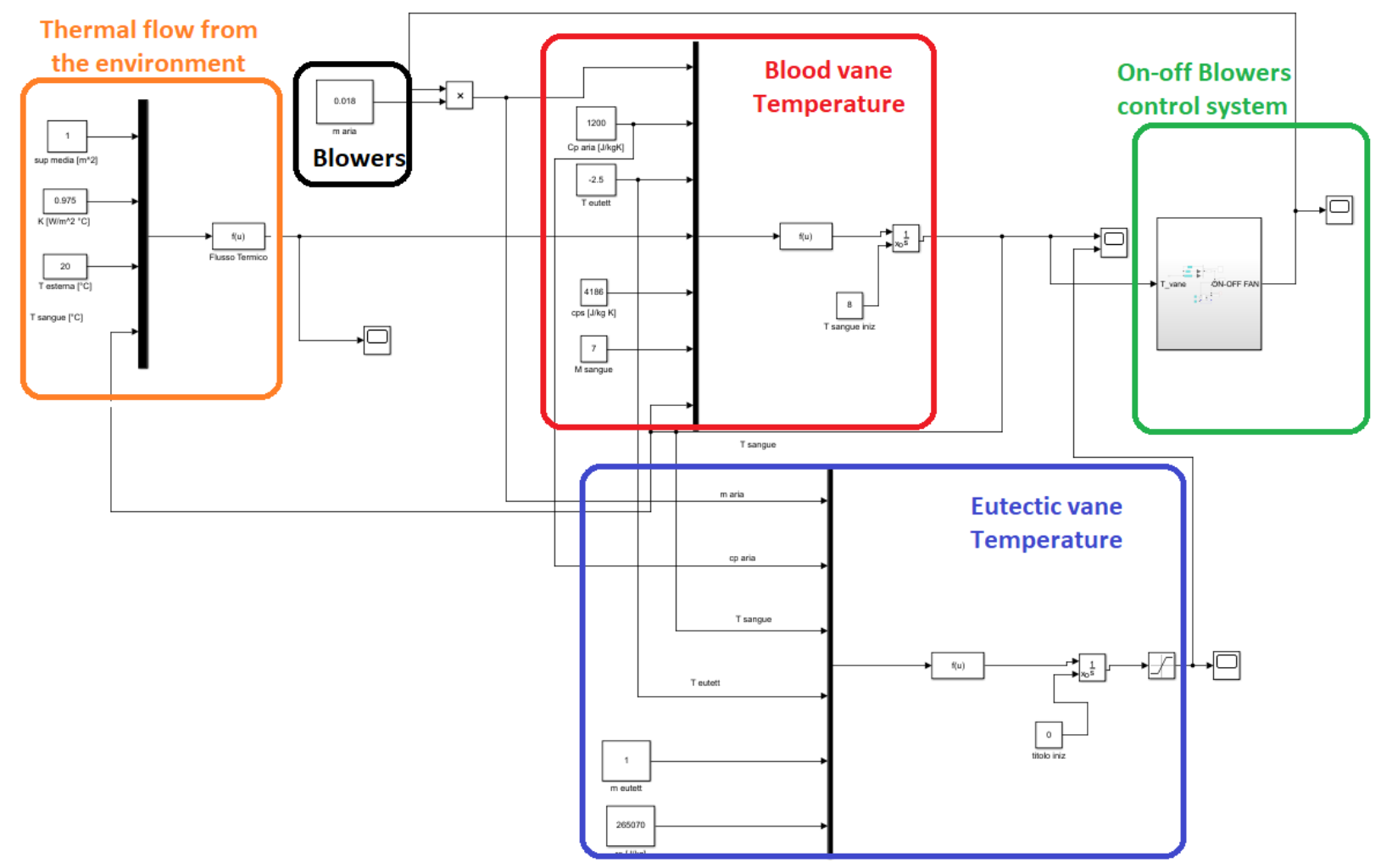

Figure 3: Scheme of the Matlab-Simulink model.

\subsection{Temperature control modelling}

In figure 4 is represented the Matlab-Simulink scheme of the onboard temperature control system. The system is designed to keep the blood compartment within the desired temperature range: $T_{\min }<T_{b l}(t)<$ $T_{\max }$.

The controlled variable is of course the blood temperature, which signal is detected by sensors in the blood compartment and delivered to the control system.

The controlling variable is the signal switching on or off the blowers.

The logics embedded in the system envisages:

- Switching off the blowers if $T_{b l}(t)<T_{\min }$;

- Switching on the blowers if $T_{b l}(t)>T_{\max }$;

- Keeping the blowers status to the previous one if the blood compartment temperature stays within the desired range: $T_{\min }<T_{b l}(t)<T_{\max }$.

This logics has been implemented by means of Matlab-Simulink blocks, namely logic blocks which provide 0 or 1 signals basing on the comparison between time varying temperature value and set-points and a multiport switch that provides the signal to the blowers according to the signals coming from the logic blocks. 


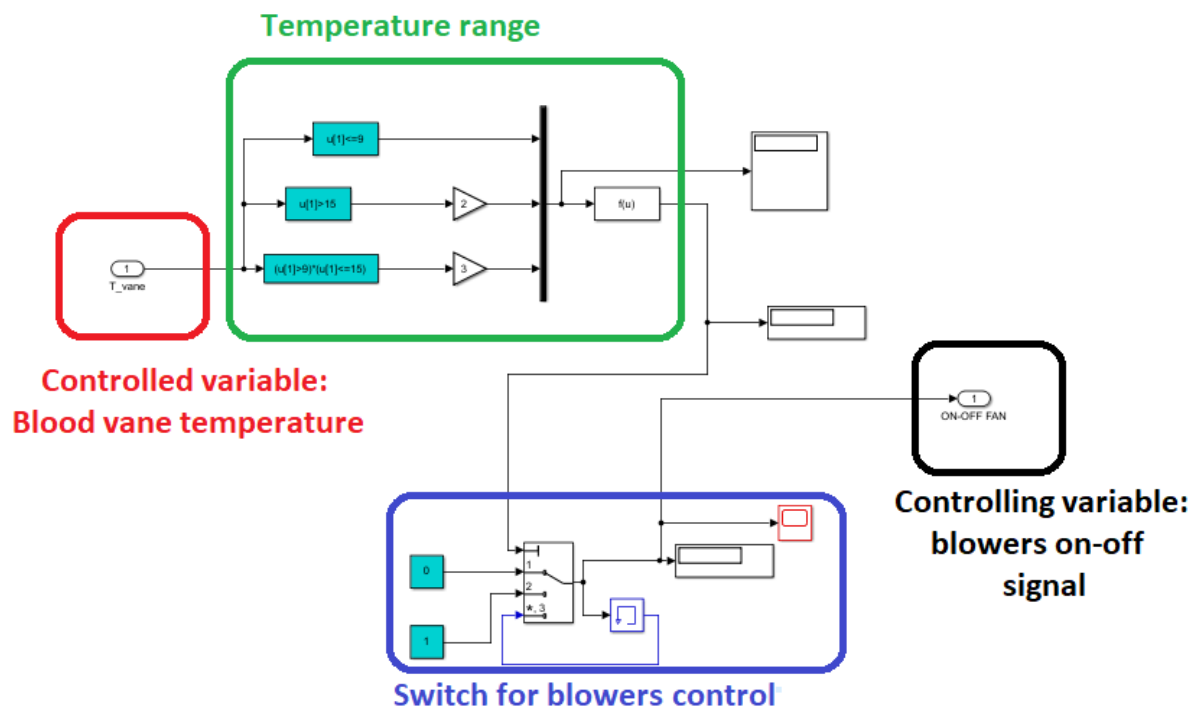

Figure 4: Matlab-Simulink scheme of the blowers control system.

It must be remarked that, in addition to the online employ during the box transports, the model can also be used in a design phase, for setting the mass of eutectic to be employed in function the mass of material to be transported, the flow rate of the circulation blowers, the type and thickness of the insulating material etc.

\section{SIMULATIONS RESULTS}

In this chapter, the blood box model is employed to simulate the transport of blood bags. To utilize the model correctly, it is necessary to define:

- The temperature range within which the blood bags must remain during the travel time; this range has been set within $4^{\circ} \mathrm{C}$ and $6^{\circ} \mathrm{C}$, to keep the maximum temperature below the dangerous value of $8^{\circ} \mathrm{C}$, above which the blood is no more usable;

- The period of the year in which the transport occurs; since the most dangerous period of the year for blood over-heating is in hot months, two different periods have been chose, namely May (with an average ambient temperature of $21^{\circ} \mathrm{C}$ ) and August (with an average ambient temperature of $\left.27^{\circ} \mathrm{C}\right)$.

Simulations for these two periods have been carried out with the purpose of monitoring the following outputs of the model:

- The temperature in function of time for the blood compartment, which needs to remain in the above mentioned range;

- The liquid mass fraction of the eutectic material, which ranges between 0 and 1 ; as soon as the liquid mass fraction reaches the value 1, the eutectic is no more available for keeping constant temperature, since its latent heat has been exhausted, and it can provide some cooling only from its sensible heat, while increasing its temperature;

- The number of interventions made by the blowers, which are switched on and off according to the temperature control system;

- The total duration of the cooling effect, which also corresponds to the period of time in which the eutectic liquid mass fraction reaches the value 1.

In the following are reported the results of the simulations carried out for the two chosen periods of the year. 


\subsection{Results for the month of May}

In figure 5 is shown the diagram of simulated blood compartment temperature in function of time.

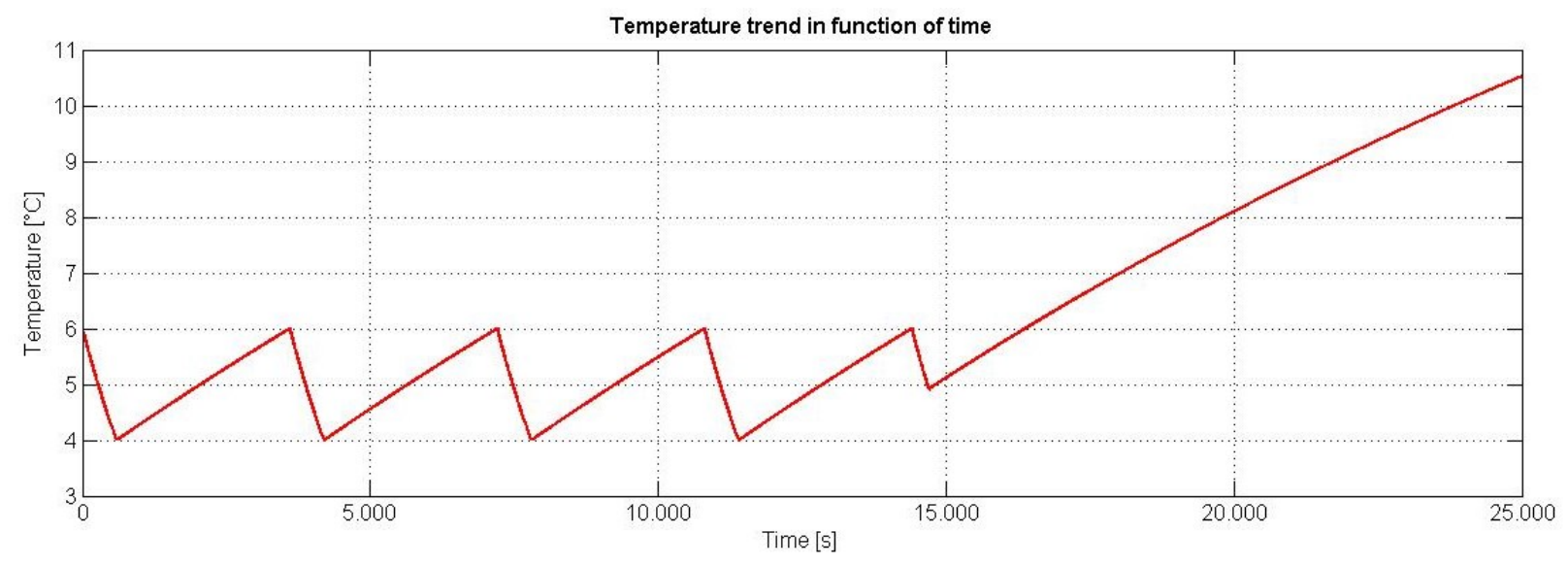

Figure 5: Blood compartment temperature in function of time for the simulation in the month of May $\left(21^{\circ} \mathrm{C}\right.$ average ambient temperature).

As visible, with the input parameters listed in the $3^{\text {rd }}$ chapter, the blood compartment maintains the correct temperature range for $16460 \mathrm{~s}(4.57 \mathrm{~h})$, and the circulation blowers are activated for 5 times. The blood can be considered unusable after the reaching of $8^{\circ} \mathrm{C}$, which occurs after $19803 \mathrm{~s}$ of simulation $(5.50 \mathrm{~h})$.

In figure 6 is represented the eutectic liquid mass fraction diagram in function of simulated time.

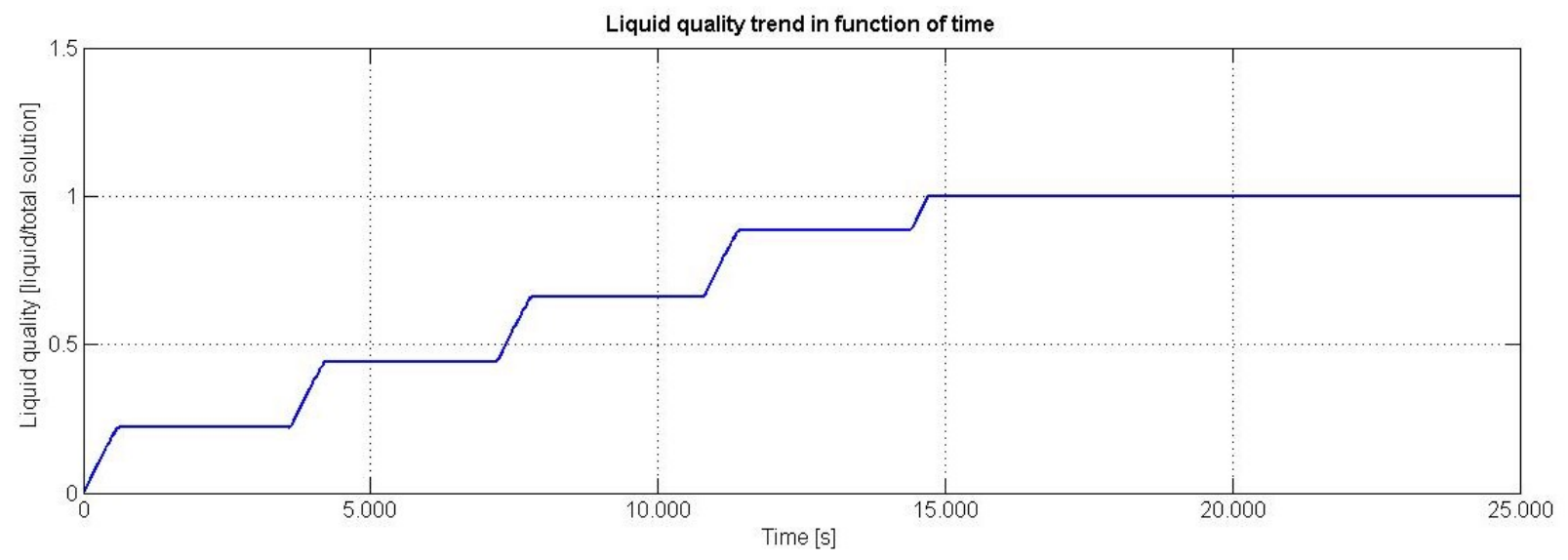

Figure 6: Eutectic liquid mass fraction in function of time for the simulation in the month of May $\left(21^{\circ} \mathrm{C}\right.$ average ambient temperature).

The eutectic reaches the limit of exhaustion at $14698 \mathrm{~s}(4.08 \mathrm{~h})$, after which the autonomy up to blood deterioration temperature $\left(8^{\circ} \mathrm{C}\right)$ is $5105 \mathrm{~s}(1 \mathrm{~h}$ and $25 \mathrm{~min})$.

\subsection{Results for the month of August}

In figure 7 is shown the diagram of simulated blood compartment temperature in function of time for the period of August. 


\section{Damiani, Revetria and Arecco}

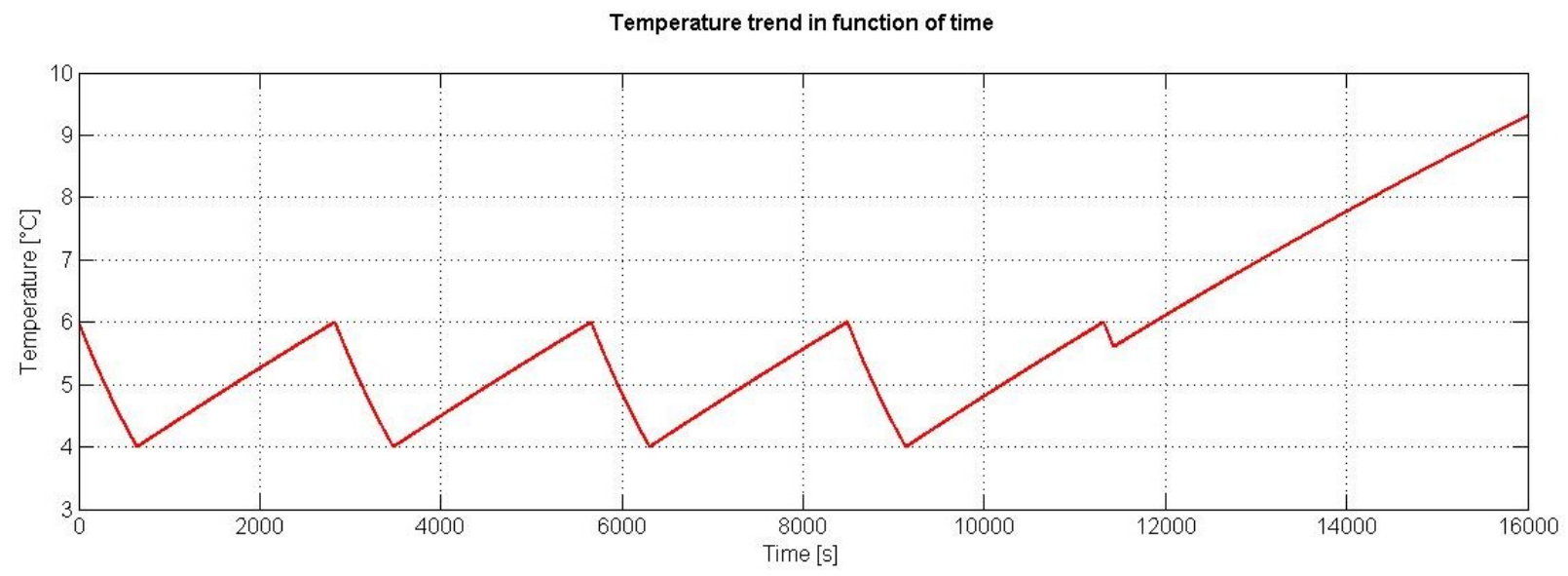

Figure 7: Blood compartment temperature in function of time for the simulation in the month of August $\left(27^{\circ} \mathrm{C}\right.$ average ambient temperature).

In the case of the hottest month, the blood compartment maintains the correct temperature range for 11950 $\mathrm{s}(3.32 \mathrm{~h})$, and also in this case the circulation blowers are activated for 5 times. The blood can be considered unusable after the reaching of $8^{\circ} \mathrm{C}$, which occurs after $14278 \mathrm{~s}$ of simulation $(3.96 \mathrm{~h})$.

In figure 8 is represented the eutectic liquid mass fraction diagram in function of simulated time.

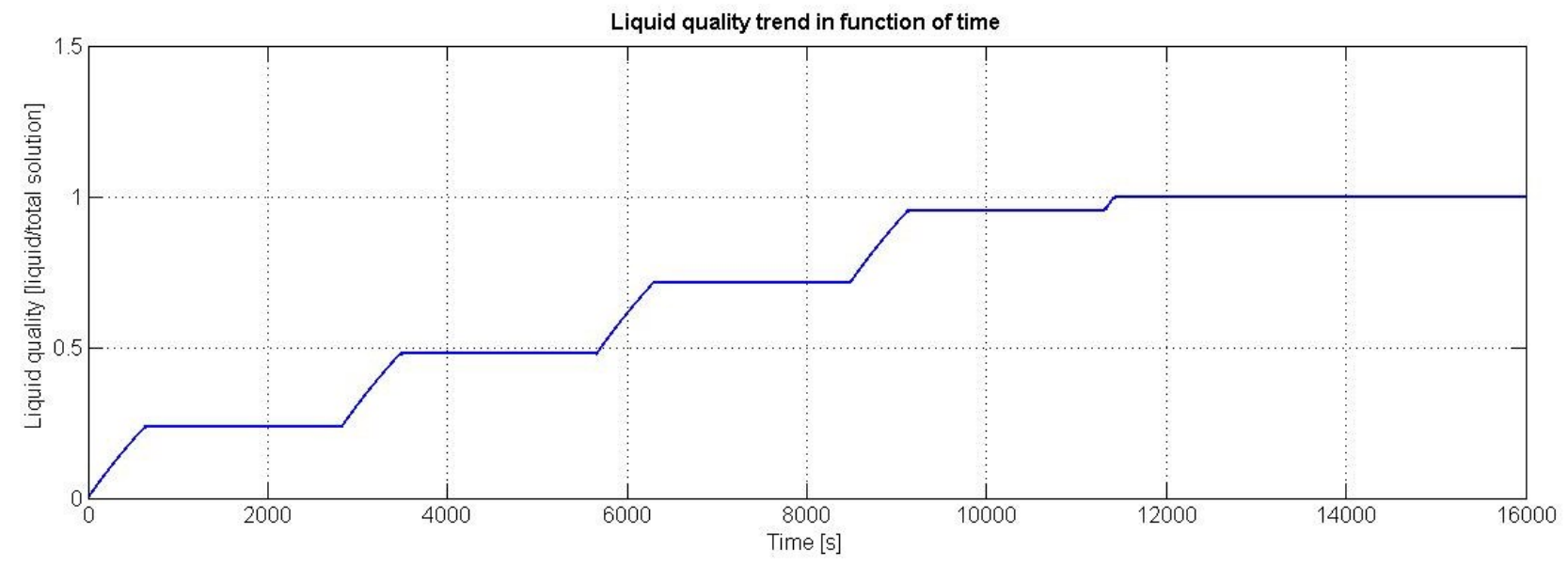

Figure 8: Eutectic liquid mass fraction in function of time for the simulation in the month of August $\left(27^{\circ} \mathrm{C}\right.$ average ambient temperature).

The eutectic reaches the limit of exhaustion at $11429 \mathrm{~s}(3.17 \mathrm{~h})$, after which the autonomy up to blood deterioration temperature $\left(8^{\circ} \mathrm{C}\right)$ is $2849 \mathrm{~s}$ (about $47 \mathrm{~min}$ ).

\section{CONCLUSIONS}

This paper presented a system for blood transport at safe temperature conditions, constituted by an insulated transport box, equipped with cooling ventilation for keeping the blood compartment within a safety temperature range and an informatics support system providing the useful data for the safe transport (e.g. the time remaining before the exhaustion of cooling effect, the logistic data of the nearest blood collection point...). 
The main topic of the paper was the construction and testing of the simulation model, implemented in the Matlab-Simulink environment, which is supposed to, on one side, allow the correct sizing of the engineering parameters for the box (eutectic to blood mass ratio, air flow rate of the blowers, walls insulation...) and on the other side, to work as an online simulation support system for the determination of the box vital parameters (temperature of the blood containment space and residual autonomy).

The simulations, carried out for two periods of the year with different average ambient temperature values, showed a satisfactory behavior of the box parameters in function of time, and demonstrated that the system is able to operate in safety for more than 4 hours in the month of May and for three and a half hours for the month of August.

Future work will face the details of cloud network interactions, the assessment of costs and simulations in more extreme environments, such as hot desert areas.

\section{REFERENCES}

Gibson, J.G., T. Sack, R.D. Evans, W.C. Peacock, The Effect of Varying Temperatures on the Post Transfusion Survival of Whole Blood During Depot Storage and after Transportation by Land and Air, The Journal of clinical investigation, 1947, Vol.26(4), pp.747-755.

Or, I., W.P. Pierskalla, A Transportation Location-Allocation Model for Regional Blood Banking, A I I E Transactions, 11 (2), 1979.

Fakhr, A.A., A. Bikmoradi, M. Zandiyh, H. Mozafari, The assessment standards related to blood transportation, storage, preparation, and administration in operating rooms of Hamedan educational treatment centers, Scientific Journal of Iranian Blood Transfusion Organization, 2012, Vol. 9 Issue 1, pp. 63-71.

Damiani, L., R. Revetria, K. Mzoughi, P. Giribone, A Hybrid Simulation Model for Evaluating Risk Related to Complex Plants in Hospitals, Proceedings of the World Congress on Engineering and Computer Science 2016 Vol II WCECS 2016, October 19-21, 2016, San Francisco, USA.

Damiani, L., P. Giribone, K. Mzoughi, R. Revetria, A Hybrid Simulation Model for Hospital Complex Plants Risk Evaluation, 2017, Engineering Letters, 25.2.

Patrone, C., L. Cassettari, L. Damiani, R. Mosca, R. Revetria Optimization of Lean Surgical Route through POCT Acquisition, IAENG Conference IMECS 2017, Hong Kong, 15 - 17 March 2017.

Castro, M., A. J. Jara, A. F. G. Skarmeta, Analysis of the Future Internet of Things Capabilities for Continuous Temperature Monitoring of Blood Bags in Terrestrial Logistic Systems, in: Lee G., Howard D., Ślęzak D. (eds) Convergence and Hybrid Information Technology. ICHIT 2011. Lecture Notes in Computer Science, vol. 6935, Springer, Berlin, Heidelberg.

Damiani, L., P. Giribone, R. Revetria, A. Pini Prato, A passive decay heat removal system for the lead cooled fast reactor demonstrator "Alfred", Progress in Nuclear Energy 83 (2015) 294-304.

Damiani, L., A. Pini Prato, Simulation of a Power Regulation System for Steam Power Plants, Energy Procedia, 45 (2014) pp. 1185-1194.

Dellachà, J., L. Damiani, M. Repetto, A. Pini Prato, Dynamic Model for the Energetic Optimization of Turbocompound Hybrid Powertrains, Energy Procedia 45 ( 2014 ) 1047 - 1056.

Damiani, L., P. Giribone, G. Guizzi, R. Revetria, E. Romano, Different approaches for studying interruptible industrial processes: Application of two different simulation techniques, Handbook of Research on Computational Simulation and Modeling in Engineering, 2015. 


\section{AUTHOR BIOGRAPHIES}

LORENZO DAMIANI is a Researcher in the Mechanical Engineering Department (DIME) of Genoa University. He holds a Ph.D. in Engineering from Genoa University, His research interests include industrial plants, modeling and simulation. His email address is Lorenzo.Damiani@unige.it.

ROBERTO REVETRIA is a Full Professor in the Mechanical Engineering Department (DIME) of Genoa University, received his Ph.D. from Genoa University, His research interests include modeling, simulation and industrial plants. His email address is Revetria.Roberto@dime.unige.it.

STEFANO ARECCO is a student in the Mechanical Engineering Department (DIME) of Genoa University. His research interests include industrial plants, modeling and simulation. His email address is Ste.Arecco@gmail.com. 